\title{
Gold Surfaces for Condensation Heat Transfer
}

\author{
James W. Westwater \\ Department of Chemical Engineering, University of Illinois, Urbana, IL., U.S.A.
}

\begin{abstract}
Ever since the discovery of dropwise condensation by Ernst Schmidt (1) in 1930, engineers have sought to use the phenomenon commercially. Early attempts gave discouraging results and the subject became rather dormant for several decades. However, recent studies with gold surfaces have revived the interest. Some of the new findings are presented in this review article.
\end{abstract}

A vapour may condense on a cold surface in either of two ways. A photograph from a 1961 study (2) is an excellent illustration of these modes (Figure 1). The cold vertical copper wall was coated on the left half with a very thin layer of organic promoter which causes steam to condense in the dropwise mode. The right side was clean, and the steam condensed in the filmwise manner. In the photograph, this latter side is completely wet with a continuous water film and the liquid flows down as an unbroken sheet. Dropwise condensation is desired, because for a given driving force (vapour temperature minus solid temperature) the heat transfer rate is much greater for dropwise condensation than for filmwise condensation.

The reason for the inferior heat transfer during filmwise condensation is understandable. The liquid layer on the surface acts as a resistance to heat conduction. In fact, the theoretical equations for describ- ing the phenomenon are based on the physics of the liquid film, its velocity profile, and its thickness at every location. The film thickness is not constant, but a typical value is about $0.04 \mathrm{~mm}$ for water. It imposes a limit on the performance of a heat exchanger operating in filmwise condensation. This particular type of limit does not exist for dropwise condensation.

During dropwise condensation, many drops are visible, but no liquid layer can be seen between them. The drops originate at tiny nucleation sites which usually are microscopic pits and scratches (3). Highspeed motion photography through a microscope reveals that the population of active nucleation sites is small for a small temperature driving force, but increases to millions per square centimetre at large temperature differences $(4,5)$. As condensation proceeds, the drops grow and coalesce with neighbours. Eventually, a drop becomes large enough to respond

Fig. I Steam condensing on copper. The right side is clean copper witl filmwise condensation. The left side has a thin coating of cupric oleate which causes dropwise condensation. The visible temperature prohe has a diameter of 1.7 mm. After (2)

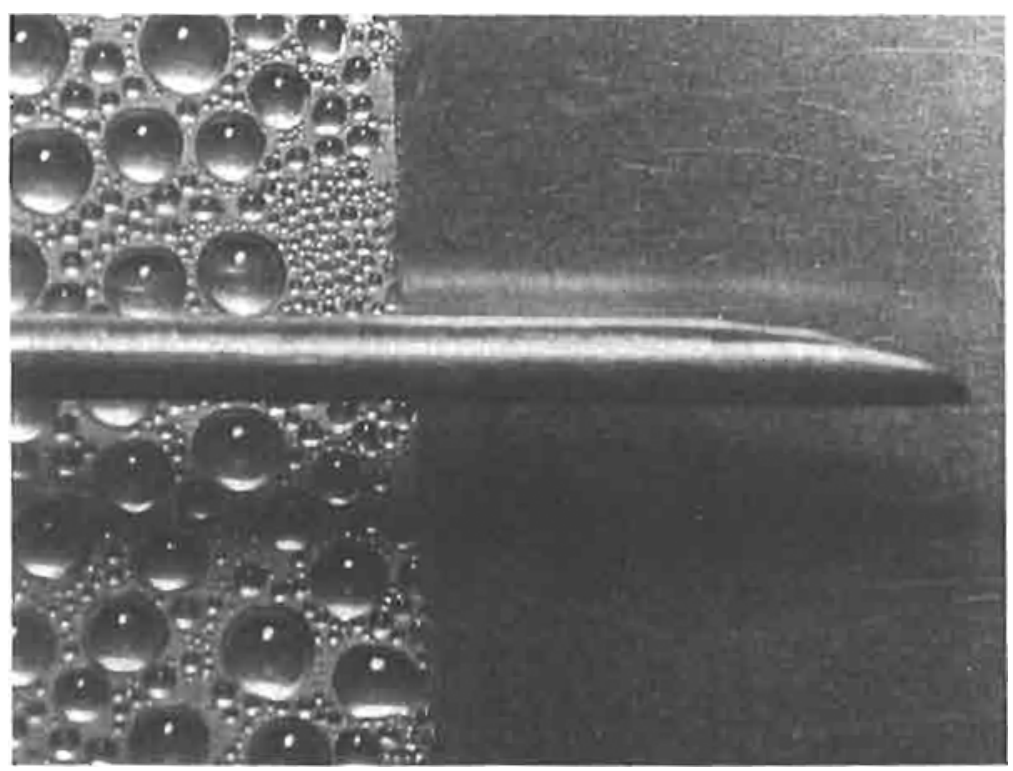


to gravity and slide down the surface. A drop may undergo as many as 400000 coalescences before it slides off.

What is between the drops? This is still a vexing question. One laboratory (6) used elliptically polarized light to examine this region. The results indicated that if a liquid layer is there, its thickness does not exceed one molecular layer. This is at least five orders of magnitude thinner than the liquid film in filmwise condensation. A different study (7) used a lightinterference technique to examine the area between drops. The results indicated a liquid layer having a thickness comparable to the wavelength of light. This is about two orders of magnitude less than for filmwise condensation, and thus constitutes a negligible resistance to heat conduction.

Most researchers agree that vapour molecules which strike the drops condense thereon, probably with 100 per cent efficiency. A number of them also adopt the idea that no liquid whatever exists between the drops. Thus, it is imagined that vapour molecules which strike the base area bounce off with no loss of energy. This cannot be literally correct, because it violates the second law of thermodynamics. Two other assumptions seem more reasonable: (a) the molecules rebounding from the base area have less energy than orginally and thus form a sub-cooled vapour which quickly condenses on nearby drops, or (b) the molecules which strike the base area are adsorbed on the solid and soon move by surface diffusion to the nearby drops. It is not known at present which view is correct.

The important fact is that the limit to the rate of heat transfer during dropwise condensation is fixed by the kinetic theory of gases, that is the rate at which the vapour molecules strike the cold surface. It is also a function of the fraction of the area covered by drops. For instance, were all steam molecules at $100^{\circ} \mathrm{C}$, 1 atmosphere, to condense as they strike a surface which is at $90^{\circ} \mathrm{C}$, a heat flux of $140 \mathrm{MW} / \mathrm{m}^{2}$ would result. This is about 400 times that expected during filmwise condensation. It is about 22 times the greatest heat flux ever reported (8) during dropwise condensation, which required a temperature difference of about $60^{\circ} \mathrm{C}$ between the steam and the condenser surface. Obviously, dropwise condensation will have commercial applications as soon as the troublesome problem of how to maintain it for long time periods is solved. Gold may offer the solution or indicate how to obtain the solution.

\section{Promoters for Dropwise Condensation}

If ordinary vapours are condensed on ordinary clean metal surfaces such as of steel or copper, condensation is always filmwise. A promoter is needed to induce the dropwise mode. Early work was carried out with organic materials such as wax, oil, grease, mercaptans and heavy-metal soaps. A long list of organic promoters can be documented. Success in obtaining dropwise condensation has been claimed for at least fifteen liquids (9) consisting mostly of those having a high surface tension, such as water, ethylene glycol and aniline. Promoted dropwise condensation has been reported on a variety of treated base metal substrates, including copper, brass, iron, stainless steel, aluminium and nickel. Unfortunately, in all of these cases, the organic promoter is washed off by the sliding drops. This has been the bugbear of dropwise condensation. Figure 2 shows the wash-off rates for two organic promoters bearing radioactive labels (10). Within 4 hours, more than 75 per cent of even the more tenacious promoter had been removed. This

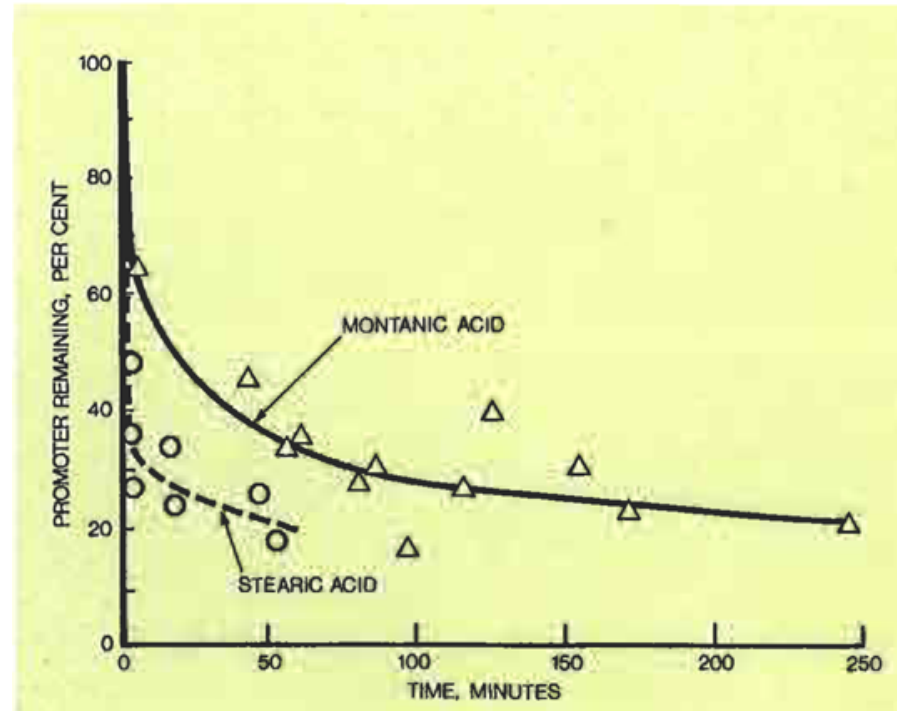

Fig. 2 Wash-off of organic promoters from copper during dropwise condensation of steam. After (10) 


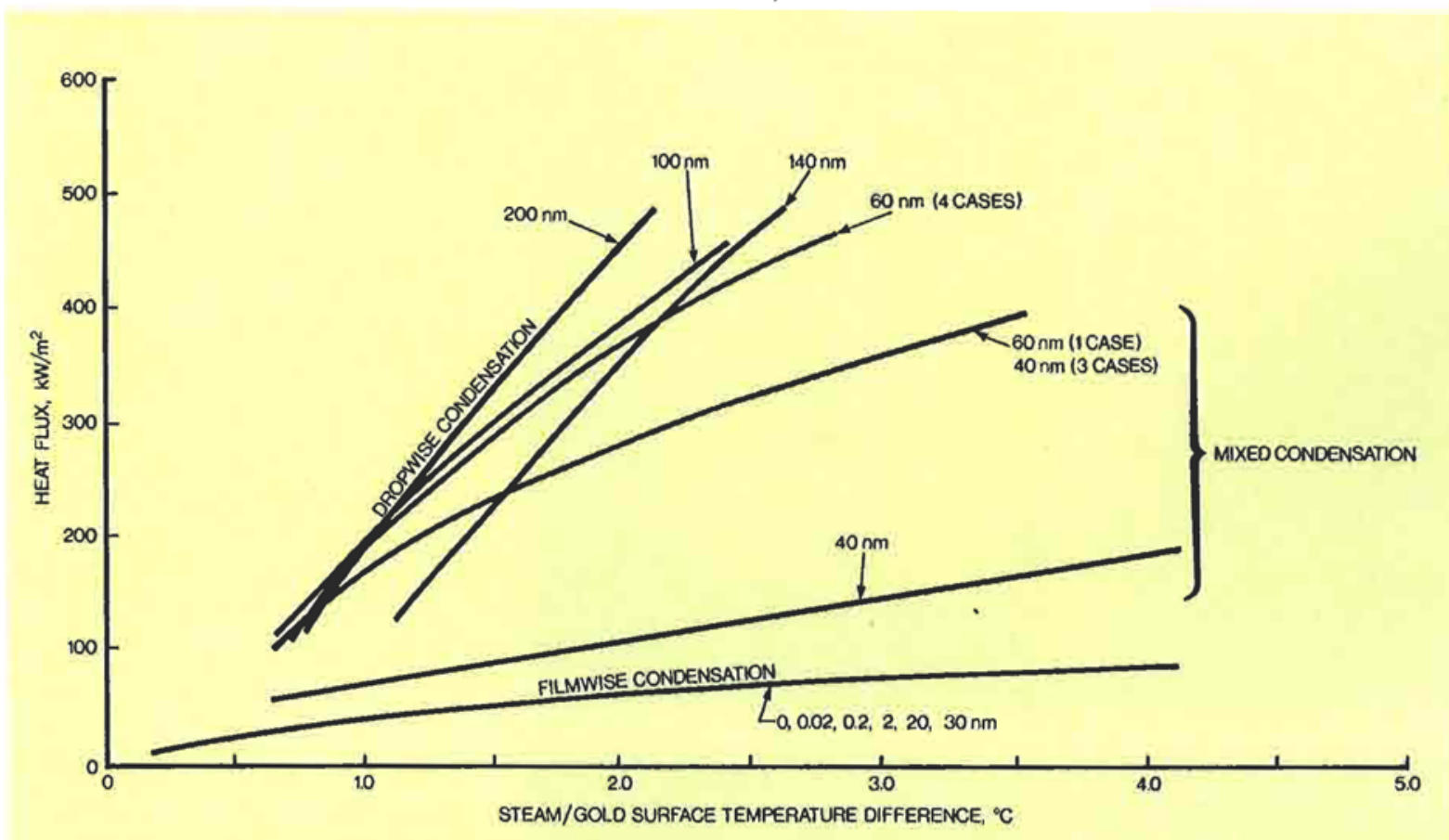

Fig. 3 Effect of thickness of gold plate on condensation heat transfer for steam. After (19)

wash-off rate is not unusual. No treatment with a promoter, whether applied by dipping, brushing or wiping, has been effective for more than a few weeks. This life is far too short for industrial use.

A long-time promotion for thousands of hours can be obtained by continuous feed of organic promoter into the vapour (for a once-through flow system) or by putting enough promoter in the boiler itself (for a recycle system). Neither scheme is acceptable to industry, mainly because of eventual contamination and possible damage to turbines and other equipment. Another scheme for permanent promotion is to coat the condenser with a silicone resin or a polymer such as polyethylene or Teflon. Unfortunately, if such a coating is thick enough to be durable, it also constitutes a barrier to heat conduction. Conversely, if it is thin enough to be an advantage for heat transfer, it eventually deteriorates, according to Bromley (11).

\section{Condensation on Gold Coatings}

Condensation on noble metals is of great interest. As reported earlier in this journal by Erb (12), dropwise condensation occurs naturally on gold, silver, rhodium and palladium. The deliberate provision of organic coatings is not required. Erb reports a life of 4.7 years for dropwise condensation on a gold electrodeposit. Other investigations of dropwise condensation on gold confirm its effectiveness $(6,13$ to 27$)$. Not only does gold have the advantage of permanence, but it has a high thermal conductivity
(1 200 times that of Teflon) and an excellent resistance to corrosion.

The high cost of gold requires its use in very thin layers on a cheaper substrate. Results from a study of condensation on gold films of various thicknesses (19) are summarized in Figure 3. In the tests, steam was allowed to condense at atmospheric pressure on the $25.4 \mathrm{~mm}$ diameter face of a vertical copper disc, cooled with water at the opposite face. Gold was electrodeposited on the copper from a proprietary alkaline gold sulphite bath containing an arsenic brightener, but claimed to be free of organic materials. The gold thickness was calculated from the plating current and time. The lower curve in Figure 3 shows that gold thicknesses of $20 \mathrm{~nm}$ or less always resulted in filmwise condensation, as was observed for clean copper. Thicknesses of $200 \mathrm{~nm}$ or more always resulted in dropwise condensation. A transition region existed for intermediate thicknesses, with part of the surface inducing filmwise condensation and part inducing dropwise condensation. The higher heat fluxes achievable with dropwise condensation compared to filmwise condensation are quite apparent from data in Figure 3. Photographs taken during tests on three gold surfaces contrast dropwise (Figure 4), mixed (Figure 5) and filmwise condensation (Figure 6). In order to show up the essential differences in the figures the lighting arrangement was such that large drops and any continuous liquid film have a dark colour. 


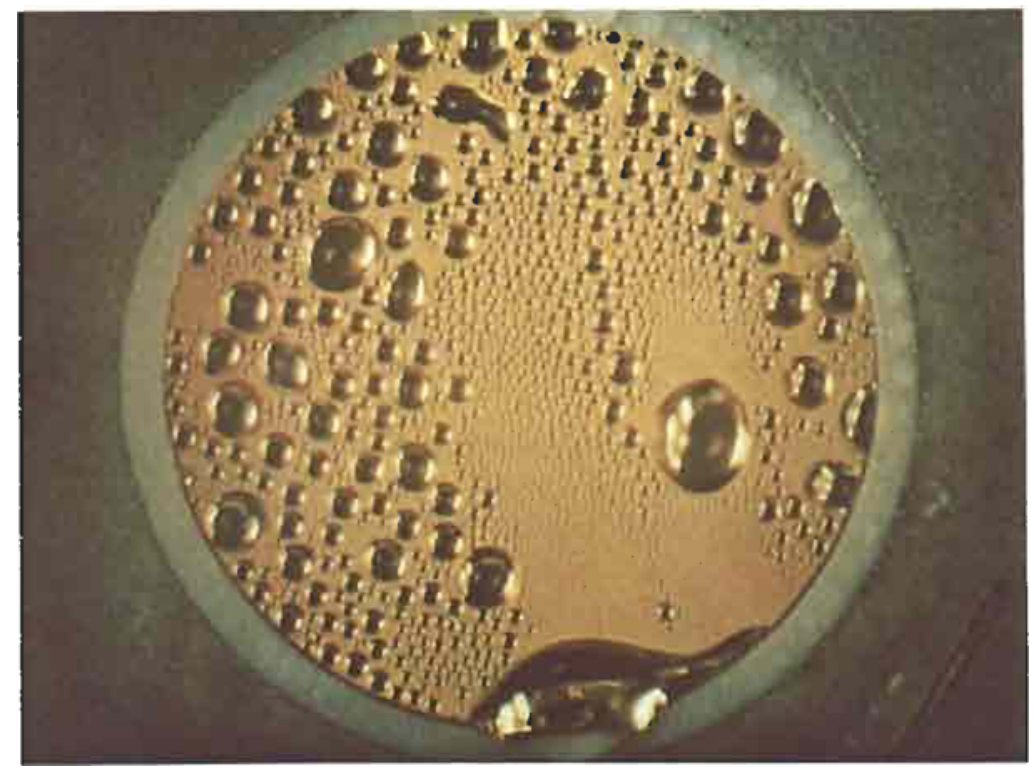

Fig. 4 Perfect dropwise condensation of steam on a $200 \mathrm{~nm}$ thick gold electrodeposit from a sulphite bath with an arsenic brightener and with no organic compound added

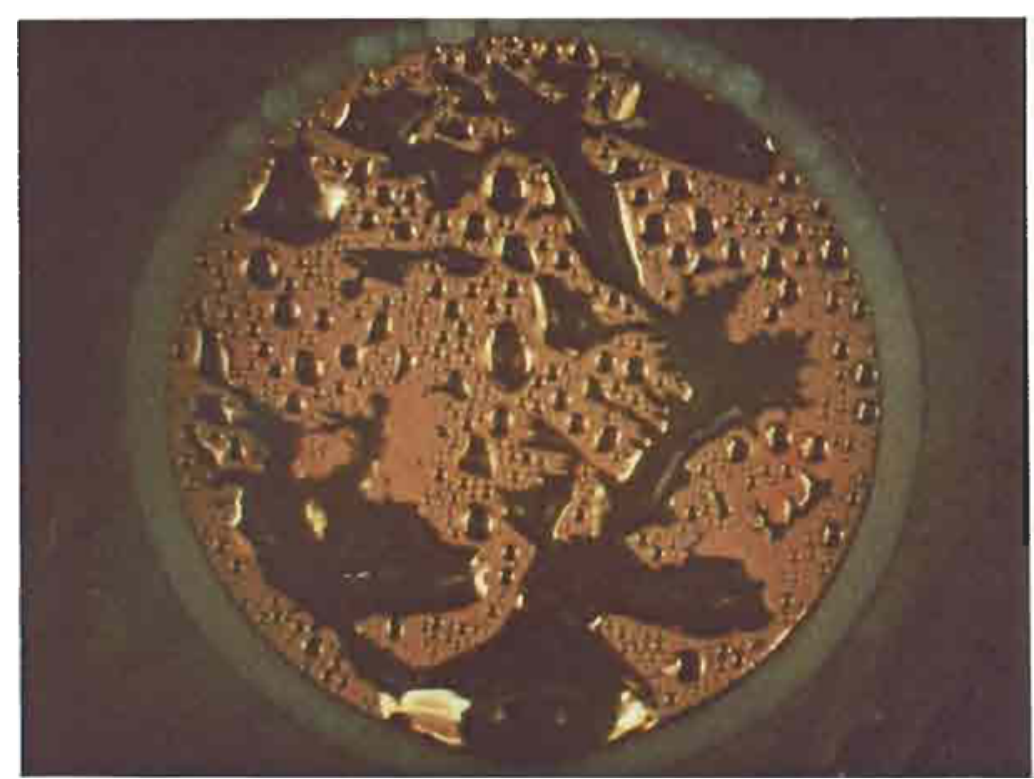

lig. 5 Mixed condensation of steam on a $100 \mathrm{~nm}$ thick gold electrodeposit from a cyanide bath without brightener

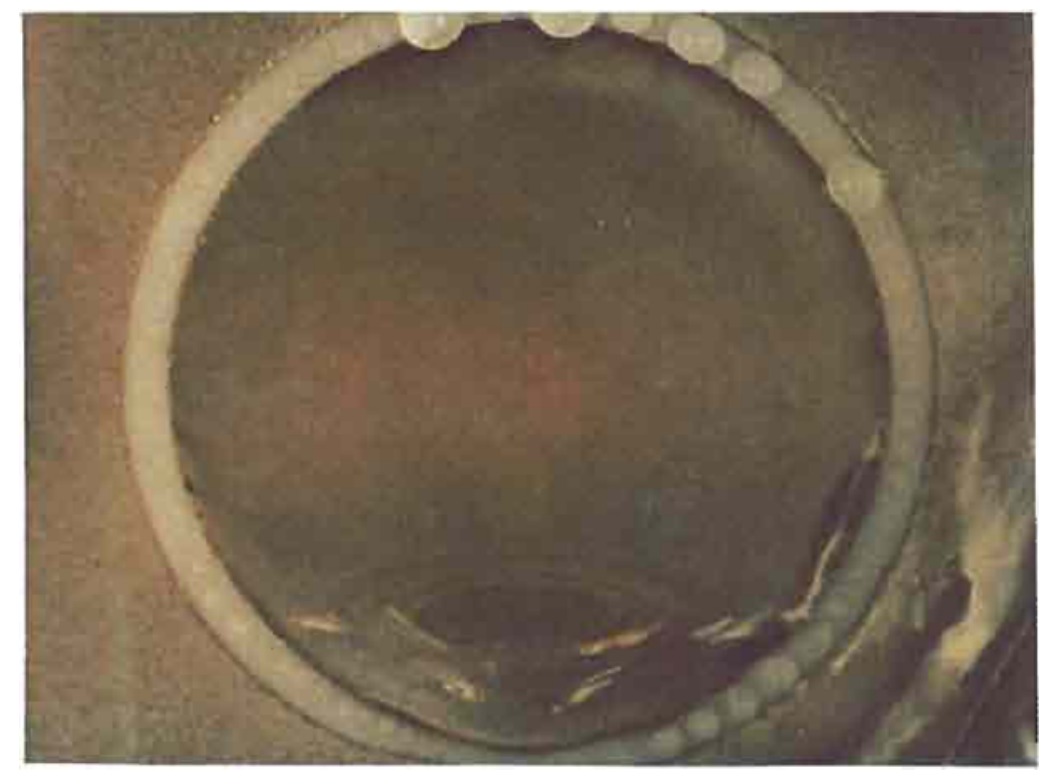

Fig. 6 Perfect filmwise condensation of steam on solid, pure gold which had been beated to $593^{\circ} \mathrm{C}$ for 1 hour and quenched 
A surprising conclusion from the standpoint of condensation is that a monolayer of electrodeposited gold atoms (about $0.2 \mathrm{~nm}$ thick) and a monolayer of organic promoter molecules have little in common. Whereas one layer of organic material suffices to cause dropwise condensation, one layer of gold has no effect. Thin electrodeposits of gold are not uniform in thickness. Electroplating is a nucleation phenomenon, with gold atoms depositing at specific nucleation sites. One 'layer' really means that the global count of atoms corresponds to that in one layer, but that the electrodeposit in some regions is thicker than one atom while other regions are devoid of gold. At least 30 or $40 \mathrm{~nm}$ of gold must be deposited before the mode of condensation of steam is affected. Roughly 100 to $200 \mathrm{~nm}$ of it are needed to produce perfect dropwise condensation.

From the economic point of view, the mass of a $\mathrm{I} \mathrm{m}^{2}$ gold layer $200 \mathrm{~nm}$ in thickness is about $4 \mathrm{~g}$, and this has a monetary value of about 77 U.S. $\$$ based on a gold price of 600 U.S. $\$ / \mathrm{oz}$.

A study of the minimum gold requirement to obtain dropwise condensation was carried out (27) varying the electroplating process. Brief consideration was also given to electroless immersion deposition and to vacuum deposition of gold on copper. It appears that a modest improvement may be achieved by optimizing the method of deposition. A minimum of $100 \mathrm{~nm}$ of gold, when deposited from an acid cyanide bath without brightener (described by the supplier as 'pure satin bright'), ensured dropwise condensation. On the other hand, a thickness of $500 \mathrm{~nm}$ was required when using acid cyanide baths brightened with cobalt or with nickel. When an alkaline cyanide bath giving 24 carat gold coatings (described by the supplier as 'pure dull') was used, mixed-type condensation occurred up to the maximum thickness tested $(250 \mathrm{~nm})$. For a gold-silver alloy from a neutral cyanide bath, mixed condensation occurred up to the maximum thickness tested $(500 \mathrm{~nm})$. With the 65 gold $/ 25$ copper/ 10 cadmium weight per cent alloy deposited from an alkaline cyanide bath, only filmwise condensation occurred, even at a coating thickness of $2000 \mathrm{~nm}$. With this ternary alloy, the deposit had a colour markedly different from that of gold. A test specimen is shown in Figure 7, and it can be seen that there is no trace of drop formation on the surface. Gold from the electroless immersion bath, a limiting thickness, neutral cyanide solution, gave mixed condensation at the maximum thickness used $(100 \mathrm{~nm})$. Gold deposited by vacuum evaporation also gave mixed condensation at the maximum thickness used $(340 \mathrm{~nm})$. It is concluded from these studies that it will be very difficult to reduce below about $100 \mathrm{~nm}$ the minimum gold thickness required to induce dropwise condensation.

\section{Condensation on Solid Gold}

A specimen of pure solid gold, $6.35 \mathrm{~mm}$ thick, was tested as a condensing surface after cleaning by various techniques which were expected to remove ordinary contaminants, especially organic materials.

Sample preparation by two techniques resulted in perfect filmwise condensation. One was immersion for $2 s$ in full strength aqua regia, a de-ionized water rinse, then immediate placement and testing in the condenser cell. The second was a 1 hour heat treatment in air at $593^{\circ} \mathrm{C}$. This should destroy organics by oxidation and evaporation. The specimen was quenched in de-ionized water and tested immediately. Figure 6 shows filmwise condensation on the heattreated solid gold.

Fig. 7 Filmwise condensation of steam on a $2000 \mathrm{~nm}$ thick electrodeposit of the 65 gold/25 copper/10 cadmium weight per cent alloy froun an alkaline cyanide bath

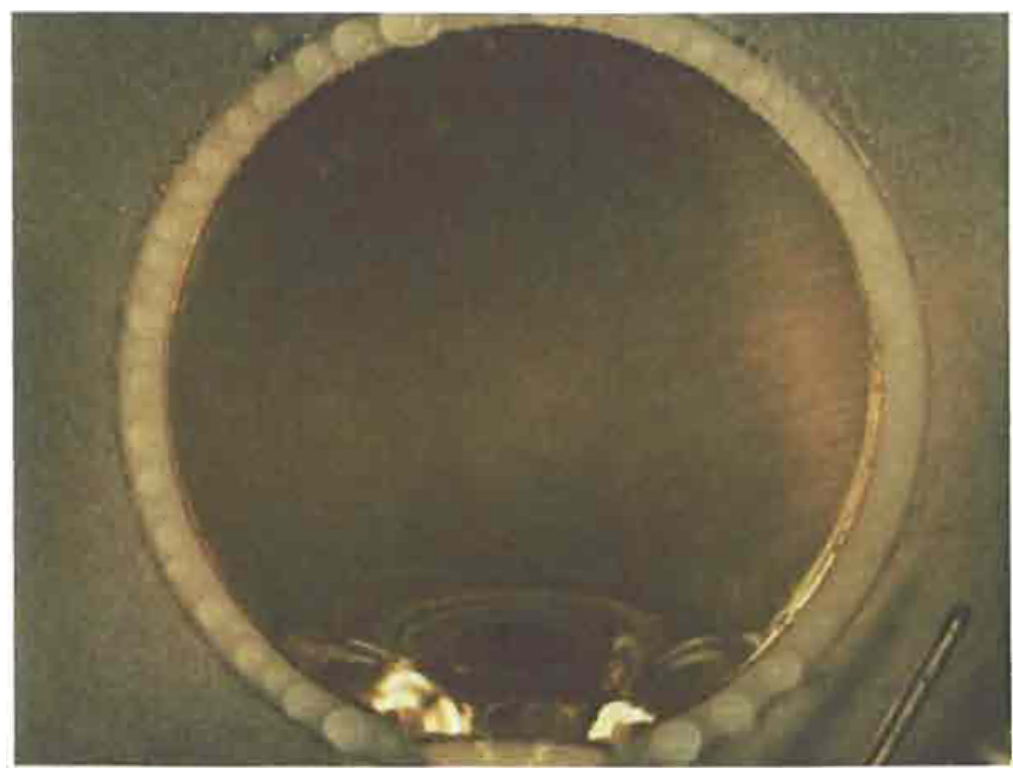




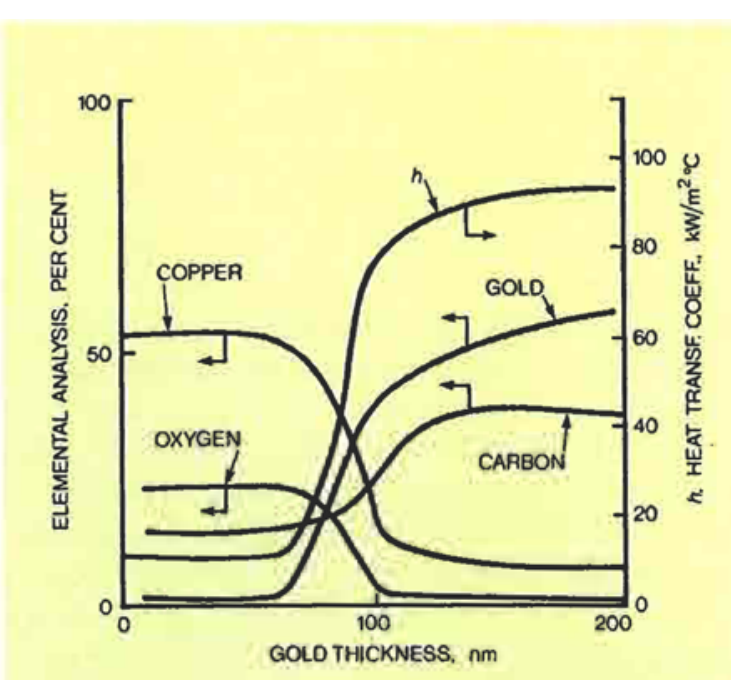

Fig. 8 Erfect of the thickness of gold electrodeposits on copper on AES results and on the heat transfer coefficient for condensation at a $\Delta T$ of $8.3^{\circ} \mathrm{C}$. The gold plating solution was of the sulphite type with an arsenic brightener, but no organic material

Two cleaning techniques resulted in dropwise condensation. One was plasma cleaning. The plasma was ionized oxygen in a high vacuum. This is very reactive and is expected to destroy organics by oxidation. After 4.5 hours of plasma cleaning, the solid gold specimen was placed immediately in the test cell. Dropwise condensation occurred on the surface. The other cleaning technique was complex; the metal was polished to a mirror finish with $50 \mathrm{~nm}$ grade alumina suspended in water, it was then soaked in ethylene dichloride, rinsed in water, soaked in methanol, rinsed in water, soaked in a boiling alkaline bath, rinsed in water, cleaned cathodically in an alkaline bath, rinsed in water, repolished with $50 \mathrm{~nm}$ alumina, rinsed in water, and then tested as a condenser. The surface was an excellent mirror and it is tempting to argue that it was free of all organic contamination. Spectroscopic experiments described below indicate otherwise.

What is the difference between a gold surface which gives dropwise condensation and one which gives filmwise condensation? Is it a matter of wettability? Smith (28) shows that since 1934 there have been at least eight studies, led by Zisman and his co-workers, which conclude that gold is wettable by water. In the same period, there were eighteen studies, led by Zettlemoyer and his co-workers, which conclude that gold is not wettable. Smith carried out a first study, with Auger electron spectroscopy (AES), to obtain direct evidence of surface cleanliness. He found that clean gold is wetted by water. He showed that less than one monomolecular layer of organic contamination causes non-wetting. He showed too that signifi- cant amounts of carbon-containing compounds are adsorbed from air in 10 minutes.

AES is a modern research tool of considerable importance. It gives the atomic analysis of a surface, but unfortunately does not identify compounds. The technique was used in conjunction with the heat transfer tests described in this article (27). Carbon, undoubtedly present as organic compounds, was detected on every surface which produced dropwise condensation. Furthermore, for electrodeposited gold on copper, the amount of carbon increased systematically with the coating thickness. Figure 8 illustrates this effect. For clean, unplated copper, AES detects mostly copper, a modest amount of oxygen and a trace of carbon. For copper plated with $200 \mathrm{~nm}$ of gold, the surface analysis reveals high concentrations of both carbon and gold. A trace of copper is detected, but oxygen is not. It may therefore be concluded that one of the effects of gold plating is to mask or cathodically reduce any oxygen originally on the surface. However the main result is that the oxygen-free gold surface adsorbs some unidentified organic compound. The organic material present may be as little as one-third of a monolayer thick, but it is held tenaciously. In our laboratory, while using a refluxing system, steam was observed to condense in perfect dropwise manner on electrodeposited gold for 2500 hours and in 75 per cent dropwise, 25 per cent filmwise manner after 6000 hours. Figure 4 shows this specimen during the first day of testing. Erb reported successful dropwise condensation for over 41000 hours (4.7 years). It is extraordinary that any organic compound should resist wash-off for that length of time.

Data in Figure 8 confirm that the heat transfer coefficient $h$ is at a low value, typical of filmwise condensation, when the gold thickness is less than about $100 \mathrm{~nm}$. The heat transfer coefficient increases abruptly at a gold thickness of $100 \mathrm{~nm}$, and takes a high value typical of dropwise condensation.

\section{Concluding Remarks}

The correlation between gold thickness, carbon amount and condensation heat transfer mode appears strong. The next big step in the study of dropwise condensation may be the identification of the organic material which spontaneously appears on the gold and which seems to be responsible for dropwise condensation. The present status of the subject is that the purer and the brighter the gold deposit, the better it serves for dropwise condensation.

\section{Acknowledgements}

Support for the recent research described in this article was provided by the U.S. Department of Energy, Grant DE-AC02 80ER 10596. The colour photographs are by D. W. Woodruff 


\section{References}

1 E. Schmidt, W. Schurig and W. Sellschopp, Tech. Mech. Thermodyn. 1930, 1, 53-63

2 J. F. Welch, Ph.D. Thesis, University of Illinois, Urbana, 196

3 J. L. McCormick and J. W. Westwater, Chem. Eng. Sci, 1965 20, $1021-1036$

4 J. F. Welch and J. W. Westwater, Proc, of Second Int. Heat Transfer Conf., 1961, 2, 302-309

5 A. C. Peterson and J. W. Westwater, Chem. Eng. Prog. Symp. Ser., 1966, 62, (64), 135-142

6 A. Umur and P. Griffith, 7. Heal Transfer, 1965, 87, 275-282

7 S. Sugawara and K. Katsuta, Proc. of Third Int. Heat Transfer Conf., 1966, 2, 354-361

8 T. Takeyama and S. Shimizu, Proc. Fifth Int. Heat Transfer Conf., 1974, 3, 274-278

9 J. W. Westwater, in 'Heat Transfer in Energy Problems', edited by W. J. Yang, Hemisphere Publishing Co., Washington, D.C., in press

10 D. W. Tanner, D. Pope, C. J. Potter and D. West, Int. Y. Heat Mass Transfer, 1965, 8, 427-436

11 L. A. Bromley, J. W. Porter and S. M. Read, Am. Inst. Chem. Eng. Y., 1968, 14, 245-250

12 R. A. Erb, Gold Bull, 1973, 6, (1), 2-6

13 R. A. Erb and E. Thelen, Ind. Eng. Chem., 1965, 57, 49-52

14 R. A. Erb and E. Thelen, in 'Proc. First Int. Symp. on Water Desalination, 1965', U.S. Department of Interior, Washington, D.C., 1967,2 , pp. $589-602$
15 R. A. Erb, F. Phys. Chem., 1968, 72, $2412-2417$

16 R. A. Erb, T. I. Haigh and T. $M$. Downing, in 'Symp. on Enhanced Tubes for Desalination Plants', U.S. Department of Interior, Washington, D.C., 1970, pp. 177-201

17 P. Griffith and M. S. Lee, Int. F. Heat Mass Transfer, 1967, 10, 697-707

18 R. E. Tower and J. W. Westwater, Chem, Eng. Progress Symp. Ser., $1970,66,(102), 21-25$

19 D. W. Woodruff and J. W. Westwater, Int. F. Heat Mass Transfer, $1979,22,629-632$

20 D. G. Wilkins, L. A. Bromley and S. M. Read, Am. Inst. Chem. Eng. 7., 1973, 19, 119-123

21 D. G. Wilkins and L. A. Bromley, Am. Inst. Chem. Eng. F., $1973,19,839-845$

22 B. T. Nijaguna and A. H. Abdelmessih, Proc. Fifth Int. Heat Transfer Conf., 1974, 3, 264-268

23 A. H. Abdelmessih, A. W. Neumann and S, W. Yang, Letl. Heat Mass Transfer, 1975, 2, 285-292

24 R. J. Hannemann and B. B. Mikic, Int. Y. Heat Mass Transfer, $1976,19,1309-1317$

25 C. M. Detz and R. J. Vermesh, Am. Inst. Chem. Eng. J., 1976, 22, $87-93$

26 M. I. Abdul-Hadi, Can. 7. Chem. Eng., 1979, 57, $451-459$

$27 \mathrm{D}$. W. Woodruff and J. W. Westwater, 'Steam Condensation on Various Gold Surfaces', accepted for 20th National Heat Transfer Conference, Milwaukee, WII, August 1981

28 T. Smith, $\mathcal{J}$. Colloid Interface Sci., 1980, 75, 51-55

\section{The Gold of Asante}

\section{THE SPLENDOUR OF A NINETEENTH CENTUR Y WEST AFRICAN KINGDOM}

During the greater part of the nineteenth century the kingdom of Asante dominated the Gold Coast of West Africa. The country was rich in gold, and although great quantities were exported to Europe it was also used liberally to adorn and to glorify its rulers.

An exhibition recently mounted by the Museum of Mankind (the Ethnography Department of the British Museum), in London, clearly brings out both this spectacular use of gold and the quite extraordinary skills of the craftsmen who made the royal insignia and many other decorative objects, these exceeding by far any such manifestation elsewhere in Africa.

The casting of gold by the lost wax process was established by the end of the fifteenth century, when European trading for gold also began. Gold was in fact the basis of life and of contacts with Europe, the country being committed to a gold-dust currency which greatly facilitated trade and which led to the production of the well known 'gold weights' cast in brass in a most attractive variety of designs.

Estimates of the amount of gold produced in this region from its earliest exploitation until the end of the nineteenth century vary widely from half a million to well over a million kilograms, some part of this always being used to adorn the country's rulers. Sword hilts, neck torques, pec-

Typical of the intricacy of Asante lost wax castings in gold from the nineteenth century is this ornament, about $8 \mathrm{~cm}$ in length, depicting three highly stylized elephants with birds on their backs. It was possibly attached to the headgear of a chief or formed part of a large ring torals, rings for fingers and toes, and many other objects were cast, some of them representing animals or insects and all showing a high standard of delicacy and intricacy.

A well illustrated book by M. D. McLeod, the Keeper of the Museum of Mankind, has been published in connection with the exhibition.

L.B.H.

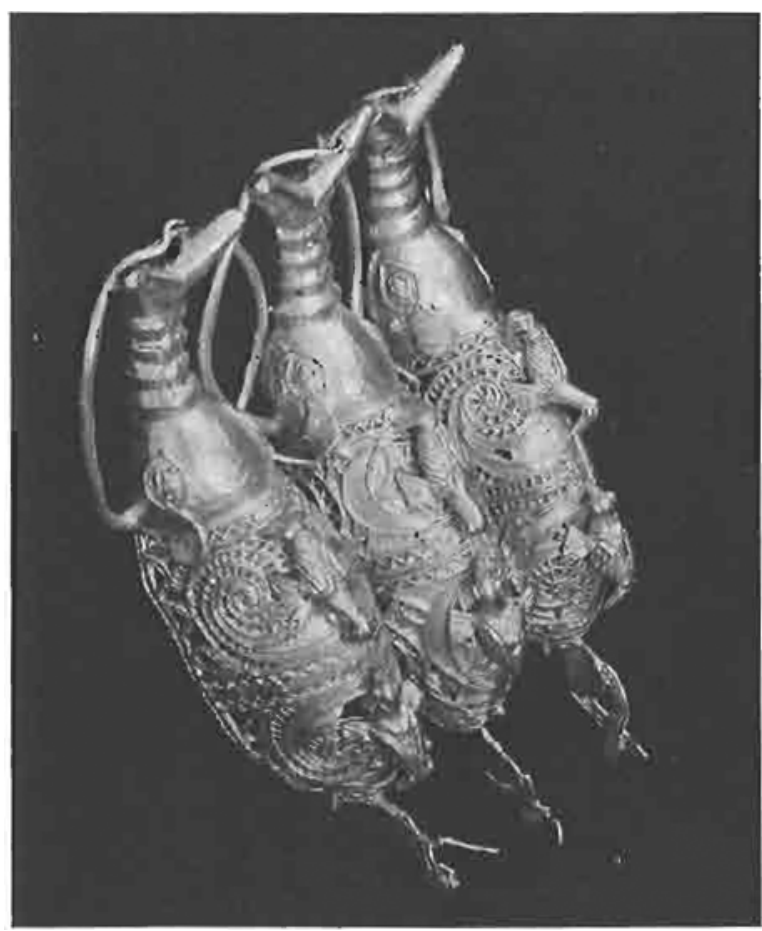

